\title{
A Comparative Study of Image Classification Algorithms for Landscape Assessment of the Niger Delta Region
}

\author{
Omoleomo Olutoyin Omo-Irabor \\ Department of Earth Sciences, College of Science, Federal University of Petroleum Resources, \\ Effurun, Nigeria \\ Email: omoirabor.omoleomo@fupre.edu.ng
}

Received 23 January 2016; accepted 5 April 2016; published 8 April 2016

Copyright (C) 2016 by author and Scientific Research Publishing Inc.

This work is licensed under the Creative Commons Attribution International License (CC BY). http://creativecommons.org/licenses/by/4.0/

(c) (i) Open Access

\begin{abstract}
A critical problem associated with the southern part of Nigeria is the rapid alteration of the landscape as a result of logging, agricultural practices, human migration and expansion, oil exploration, exploitation and production activities. These processes have had both positive and negative effects on the economic and socio-political development of the country in general. The negative impacts have led not only to the degradation of the ecosystem but also posing hazards to human health and polluting surface and ground water resources. This has created the need for the development of a rapid, cost effective and efficient land use/land cover (LULC) classification technique to monitor the biophysical dynamics in the region. Due to the complex land cover patterns existing in the study area and the occasionally indistinguishable relationship between land cover and spectral signals, this paper introduces a combined use of unsupervised and supervised image classification for detecting land use/land cover (LULC) classes. With the continuous conflict over the impact of oil activities in the area, this work provides a procedure for detecting LULC change, which is an important factor to consider in the design of an environmental decision-making framework. Results from the use of this technique on Landsat TM and ETM+ of 1987 and 2002 are discussed. The results reveal the pros and cons of the two methods and the effects of their overall accuracy on post-classification change detection.
\end{abstract}

\section{Keywords}

Land Cover, Supervised and Unsupervised Classification Algorithms, Landsat Images, Change Detection, Niger Delta 


\section{Introduction}

The Niger Delta region of Nigeria has experienced accelerated changes induced by natural and anthropogenic disturbances. Prior to the discovery of crude oil in 1954, the region was popular for agriculture and forestry. Industrialization particularly linked to ongoing oil exploration and exploitation activities transcending over forty years, has affected the region positively by job creation and negatively by environmental degradation. Environmental changes arising from oil activities such as deforestation, urban areas alteration can be detected using remotely sensed data. The underlying premise for using remote sensing data is that a change in the status of an object must result in a change in radiance value [1] [2].

Land cover classification and change detection have been conducted by [3] and [4], using unsupervised ISODATA classification algorithm, while [5] and [6] use the maximum likelihood supervised classification method. In Nigeria, [5] compared different supervised classification algorithms to monitor landscape changes in Abuja. His findings reveal that the maximum likelihood algorithm performs better than the other methods used. Environmental change detection of the Niger Delta region using remotely sensed data has been conducted by [6]-[8]. They reported LULC decline particularly in the mangrove and forest areas while agricultural land and built-up areas increased.

Remote sensing deals with the knowledge and techniques used to analyse, interpret, monitor and manage environmental changes, using optical and microwave imagery from various kinds of sensors [9]. Remote sensing capability is enhanced, by being a component of Geographic Information Systems (GIS). These systems are powerful sets of tools for collecting, storing, retrieving at will, transforming and displaying spatial data from the real world [10]. Given the spatial nature of land degradation, GIS provides an integrative tool for the generation, storage and presentation of relevant information. It can be further utilized in assessing the impact of crude oil activities such as exploration, exploitation and production through the interaction of a database with various environmental indices. This paper compares two parametric classification algorithms in estimating the changes that have occurred in the study area between 1987 and 2002. The research approaches the use of remote sensing data from their ability to discriminate changes in the environment as a result of natural and anthropogenic activities.

\section{Study Area}

The area of interest lies within latitudes $5^{\circ} 10^{\prime} 39^{\prime \prime} \mathrm{N}-5^{\circ} 41^{\prime} 19^{\prime \prime} \mathrm{N}$ and longitudes $5^{\circ} 35^{\prime} 599^{\prime \prime} \mathrm{E}-6^{\circ} 06^{\prime} 09^{\prime \prime} \mathrm{E}$ and is contained in the triangle of Niger Delta region of Nigeria (Figure 1). Its geology is the product of both fluviatile and marine sediment build-up during the upper Cretaceous. Three major depositional cycles have occurred in the region leading to the deposition of the Akata, Agbada, and Benin Formation. The Agbada Formation is rich in hydrocarbon. The relief is low lying and built on the successive sedimentation of four physiographic units fresh water swamp, mangrove swamp, coastal plains and the upland Niger valley. Soils are generally hydromorphic and poorly drained. The pristine vegetation has been reduced considerably in the area and replaced by mosaic of secondary re-growth such as arable farmlands (cassava, maize, yam) and tree crops (oil palm, rubber,

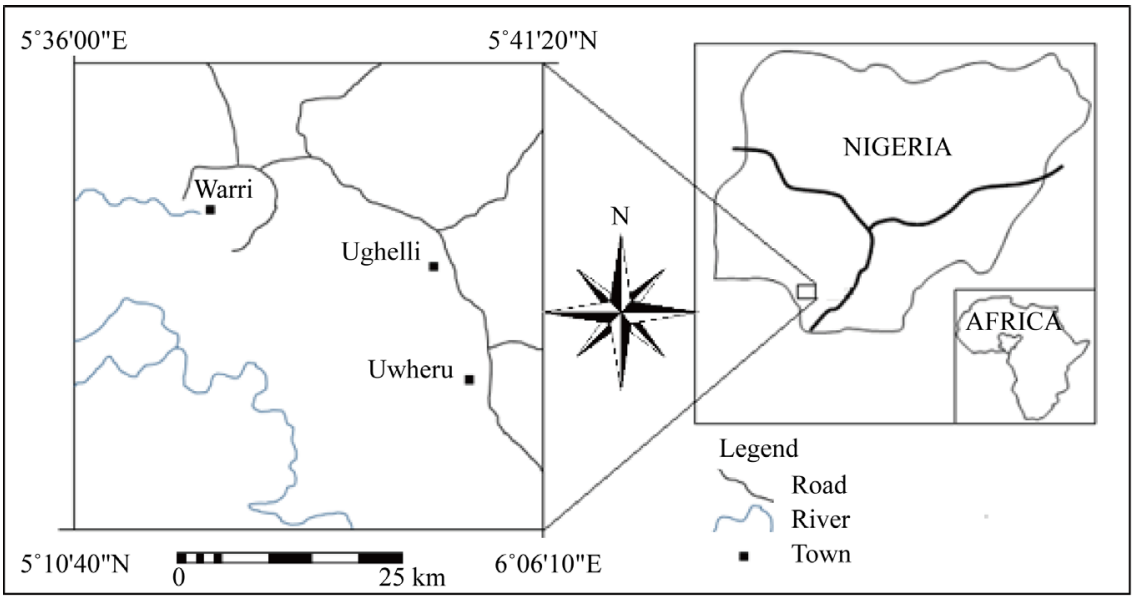

Figure 1. Map of study area. 
cocoa, plantain). The remaining natural vegetation still occur as fresh water swamp forest, mangrove swamp forest and ever green lowland rainforest a major source of timber. The River Niger is the major drainage system from which other discrete river systems originate. The region has a humid equatorial climate. The cloud cover is high, with relative humidity and average rainfall above $80 \%$ and $3000 \mathrm{~mm}$ respectively.

\section{Data Sets}

The satellite images used in this study consist of one scene from the Worldwide Reference System (WRS-2) of path 189 and row 056. Orthorectified images of Landsat-5 Thematic Mapper (TM) and Landsat-7 Enhanced Thematic Mapper plus (ETM+) acquired on the 21-12-87 and 28-12-2002, respectively. The images were obtained from [11]. The bands used for the analysis include 1 - 5 and 7. Bands 2, 4 and 7 were used to make the colour composite as the combination gave a natural colour composite. Geometric correction of the images was already done by NASA using the UTM map projection, World Geodetic System 1984 datum and WRS 84 ellipsoid. The final orthorectified images produced accurate images having root mean square (RMS) geodetic accuracy of better than $50 \mathrm{~m}$ [12]. Subsets from the original scene were then extracted for the two images for further analysis. Digital map containing land use/land cover information was used to select test data for the Landsat TM 1987 and Landsat ETM+ 2002 image classification. Additionally test data for the Landsat ETM+ 2002 classification were acquired from field visit with the aid of GPS.

\section{Methods}

The methodology used for detecting changes in the landscape include, selection of classification system, image classification, and post-classification change detection (Figure 2).

\subsection{Selection of Classification System}

Before any useful thematic information can be extracted from remote sensing data, a LULC classification system has to be developed to obtain the classes of interest to the analyst [13]. A number of classification sys-

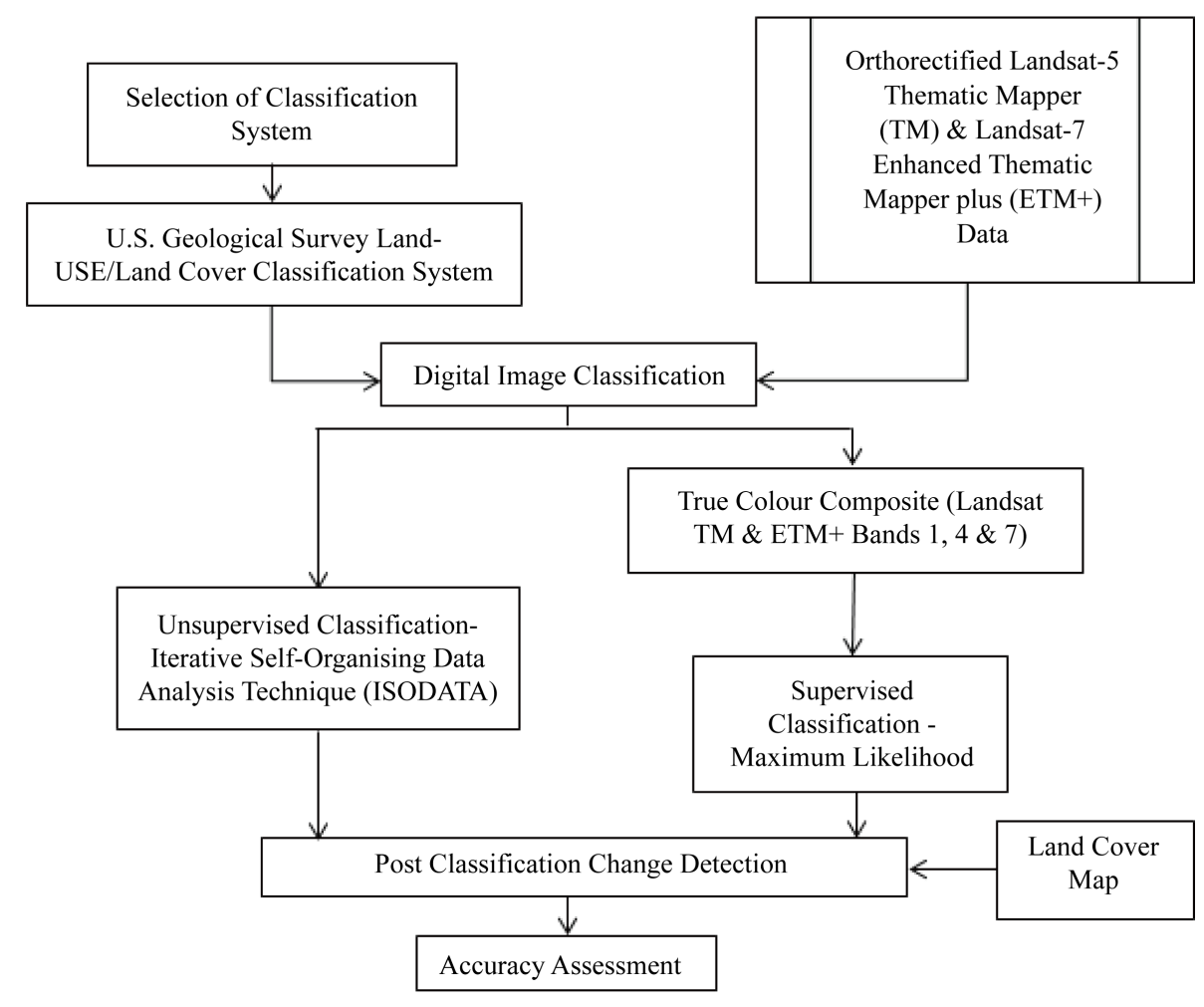

Figure 2. Flowchart of methodology for landscape change detection. 
tems already exists for LULC, they include the US Geological Survey Land-Use/Land Cover Classification System [14], Coordination of Information on the Environment (CORINE) land cover [15], and Food and Agriculture Organization (FAO) land cover classification system (LCCS) [16]. While land cover refers to the type of material present on the landscape, land use on the other hand is what is done on the land [17].

Since there are already in existence reputable classification systems, such as those listed above, it would be meaningless to develop a system that would be useful only for the purpose of this research. The commonly used US Geological Survey Land-Use/Land Cover Classification System [14] was thus modified for the preparation of the legend for the LULC maps. Since $30 \mathrm{~m}$ resolution images were used for the classification, the following 6 land use/land cover classes were derived; built-up/bare area, agricultural land, forest, wetland, water and sediments.

\subsection{Digital Image Classification}

Selection of the most appropriate algorithm for land cover classification from satellite data will depend on specific circumstances and available resources [18]. The unsupervised-ISODATA and supervised-Maximum Likelihood classification algorithms were used for this analysis. For the unsupervised classification, the Multispec software Windows NP/XP version 3.1 was used. It is a processing system for interactively analyzing Earth observational multispectral image data such as that produced by the Landsat series of Earth satellites and hyperspectral image data from current and future airborne and spaceborne systems [19]. The ILWIS software version 3.3 was used for supervised classification and GIS analysis.

\subsubsection{Unsupervised ISODATA Classification}

Unsupervised algorithms often attempt to find groups or clusters in data that are spectrally similar. The basic assumption in unsupervised classification is that values with a given cover type should be close together in the measurement space, whereas data in different classes should be comparatively well separated [20]. The resulting clusters do not necessarily have any relationship with the classes of informational value they only assist in obtaining a list of classes that are exhaustive. Therefore, the results of the classification must be compared to some reference data for meaningful interpretation. The Iterative Self-Organising Data Analysis Technique (ISODATA) clustering algorithm is a modification of k-means clustering algorithm [17]. It uses minimum spectral distance to assign a cluster for each potential pixel.

The number of classes is the most significant of the clustering parameters [3]. If too small, relatively broad clusters may be generated which may not produce true results. If the number is too big, very pure clusters may be yielded with highly demanding computational resources and substantial increase in time required for cluster labeling [4]. The final number of classes chosen for this study was 40 . The other required parameters include the maximum percentage of pixels whose class values are allowed to remain unchanged between iterations and the minimum cluster size. 99\% and 7 were chosen for convergence value and minimum cluster size respectively. A value of 100 was selected as the threshold value. This implies that the system is forced to assign every pixel in the image to one of the clusters. A value of less than 100 results in some pixels not being assigned to clusters [21]. The classification result arranges and assigns clusters in order of descending level of brightness. Lastly, a true colour scheme resembling that of the original image was then used to assign colour to the different classes with the aid of digital vegetation, land use maps and ground truth data.

\subsubsection{Supervised Maximum Likelihood Classification}

ML is the most commonly used supervised classification and is it based on the assumption that the training data statistics in each band are normally distributed. It considers the distances towards class means and calculates the variance-covariance matrix of each class. Supervised classification begins with defining the areas that will be used as training sites for the different land cover classes. Training vectors must be at least unimodal and must not exhibit multicollinearity [22]. They also require a large training data set which can be very costly and generally not possible to add incrementally to the training data while training the classifier. A minimum of 15 samples was selected for each class. Ideally, the number of pixels selected should be more than 10 times as many pixels as there are bands in the image to be classified [17]. This was made with several training sites for the more training site selected, the better the results gained. The display of feature space using bands 2 and 3 aided in the discrimination of pixels for the different classes. 


\subsection{Post-Classification Change Detection}

Change detection is the process of identifying differences in the state of an object or phenomenon by observing it at different times [23]. Successful use of satellite remote sensing for land cover change detection depends upon an adequate understanding of landscape features, imaging systems, and information extraction methodology employed in relation to the aims of analysis [3]. The selection of an appropriate change detection algorithm is essential because it has a direct impact on the type of classification to be performed and whether important change information can be extracted from the image [17]. A post classification change detection method was applied. Although the accuracy of post-classification methods is dependent on the accuracy of the individual classifications and is subject to error propagation, the classification of each date of imagery builds a historical series that can be more easily updated and used for applications other than change detection [24]. Also, this method avoids the problems that arise due to variation in sensor characteristics, atmospheric effects, solar illumination angle sensor view angle and vegetation phenology between dates since each image is independently classified [25].

\section{Results and Discussion}

Figure 3 shows the results of unsupervised ISODATA and supervised ML classification for Landsat TM 1987

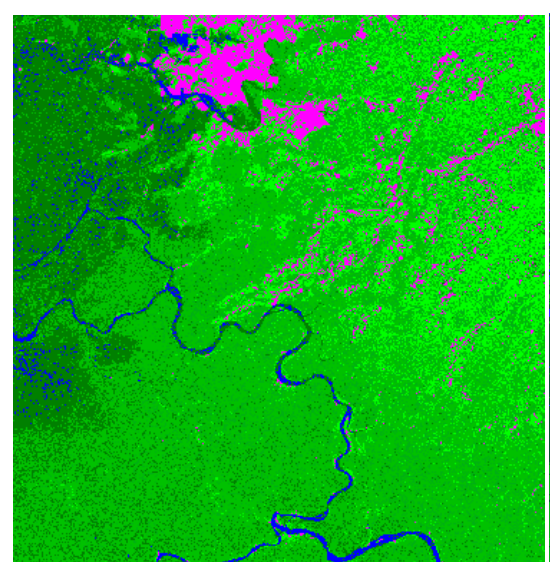

ISODATA 1987

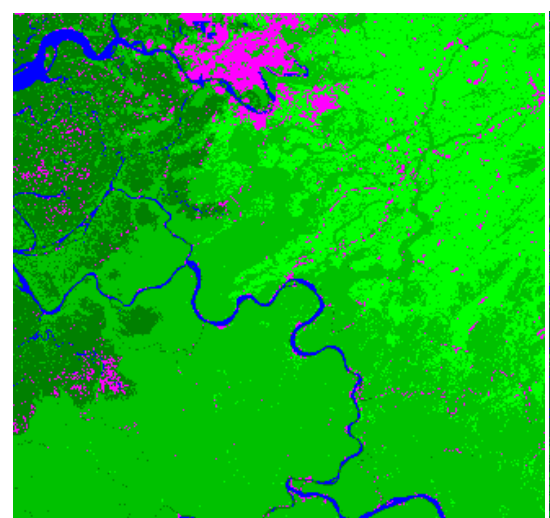

MAXIMUM LIKELIHOOD 1987

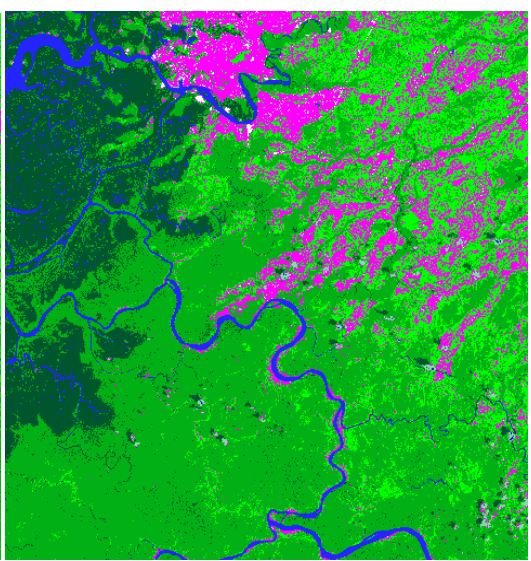

ISODATA 2002

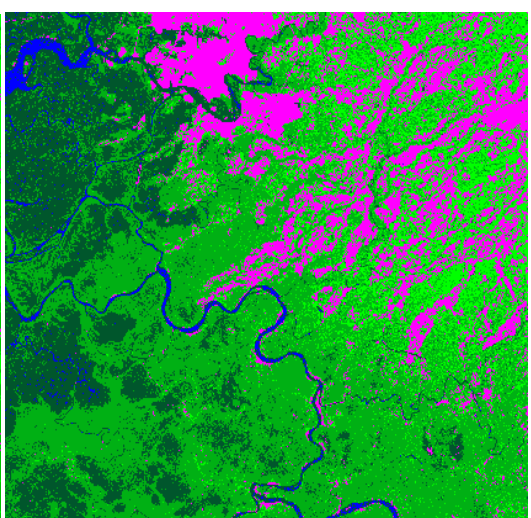

MAXIMUM LIKELIHOOD 2002

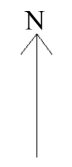

for 1987 and 2002 images

Figure 3. Unsupervised and supervised classification for 1987 and 2002 images. 
and ETM+ 2002. A comparison of the classified images reveals that the unsupervised ISODATA algorithm performed better than the ML as it gave a close semblance to the Land cover map used (Figure 4). The accuracy assessment of the unsupervised 1987 and 2002 maps gave over all accuracies of $61.29 \%$ and $69.33 \%$ respectively. The low values were as a result of misclassification between built-up/bare areas and forest in the 1987 image, while the misclassification between wetland and shadow affected the 2002 image. Since the post classification accuracy is dependent on the initial accuracies of the classified maps, this implies a reduced accuracy using the maximum likelihood algorithm. The classified maps derived from ISODATA were therefore used to compute the changes for the different LULC categories.

Table 1 shows the total LULC change between 1987 and 2002 using the ISODATA algorithm. The greatest change of $30.9 \%$ equivalent to 34,414 ha of forest disappeared within the 15 year period. Wetland, made up of mainly Mangrove trees experienced the second largest decline of 6.2\% (1637 ha). Shadow in the 2002 image was misclassified as wetland, thus giving an erroneous estimate. All other classes showed increase in cover change, with sediments topping the group with $17 \%$ (190.4 ha). The presence of clouds increased the amount of sediments in the 2002 image. Built-up/bare areas and agricultural land increased by $12.3 \%$ (4108.1 ha) and 12.1\% (16411.1 ha) respectively. Water bodies increased by 6.7\%, this could be attributed to the classification of shadow as water bodies in the 2002 image.

\section{Conclusion}

This paper presents the applications of two parametric classification algorithms in monitoring land use and land cover change. ISODATA and ML classification algorithms are based on the traditional pixel-based techniques. ML depends on the visual interpretation of the land cover types on satellite image, while ISODATA is an iterative procedure that clusters pixels based on a certain threshold. The ISODATA algorithm performed better than the Maximum Likelihood as it was able to discriminate between the different land cover classes. The area of interest has experienced the greatest change of $30.9 \%$ equivalent to 34,414 ha of forest which disappeared within the 15 year period. The deficiency experienced by ML lies in its inability to discriminate texturally due to the occurrence of mixed classes. Since they both have their limitations, it is therefore recommended to utilize both during image analysis techniques bearing in mind their strengths and weaknesses. Further research will therefore

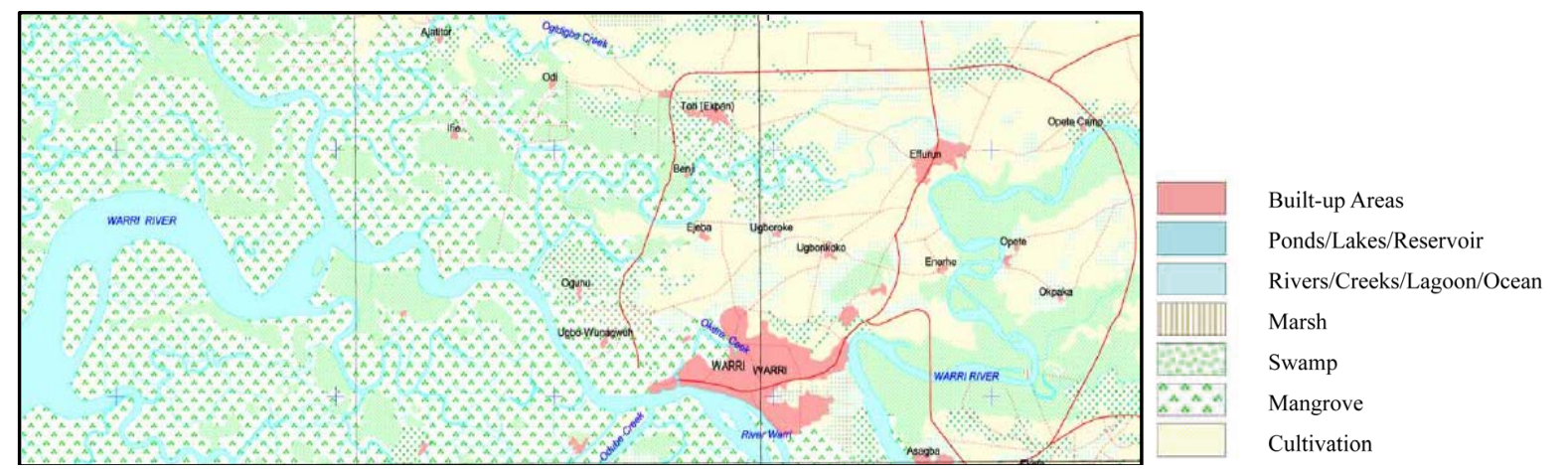

Figure 4. Land cover map of part of study area of 1990.

Table 1. Percentage change for LULC classes between 1987 and 2002.

\begin{tabular}{cccc}
\hline LULC classes & Area of classes 1987 image (ha) & Area of classes 2002 image (ha) & Change (\%) \\
\hline Agricultural land & $118,834.8$ & $135,245.9$ & 12.1 \\
Built-up/bare areas & $29,178.9$ & $33,287.0$ & 12.3 \\
Forest & $145,940.2$ & $111,525.8$ & -30.9 \\
Wetland & $28,016.2$ & $26,379.0$ & -6.2 \\
Water & $11,115.6$ & $11,914.1$ & 6.7 \\
Sediment & 928.4 & 1118.8 & 17.0 \\
\hline
\end{tabular}


be carried out in the study area using a hybrid method that incorporates both algorithms. More reference data are required to improve the post-classification results. This paper also revealed the importance of temporal and spatial remote sensing data and GIS tools in detecting the degradation of the environment from development activities in the region. The depletion of forest and mangrove can be attributed to logging, farming activities and industrialization especially by oil exploration and production companies, while the presence of oil companies in the region has attracted labour thus increasing urbanisation.

\section{Acknowledgements}

The support rendered by Petroleum Technology Development Fund (PTDF) is highly appreciated. The authors recognize the assistance of Purdue University, USA for providing the free Multispec software and also the Global Land Cover Facility (GLCF), University of Maryland for providing Landsat TM and ETM+ images.

\section{References}

[1] Hall, O. and Hay, G.J. (2003) A Multiscale Object-Specific Approach to Digital Change Detection. International Journal of Applied Observation and Geoinformation, 4, 311-327. http://dx.doi.org/10.1016/S0303-2434(03)00010-2

[2] Al-Quraishi, A.M.F., Hu, G.D. and Chen, J.G. (2004) Land Degradation Detection, Mapping and Monitoring in the Northwestern Part of Hebei Province, China, Using RS and GIS Technologies. Map Asia Conference 2004, Beijing, 26-29 August 2004.

[3] Yang, X. and Lo, C.P. (2002) Using a time Series of Satellite Imagery to Detect Land Use And land Cover Changes in the Atlanta, Georgia Metropolitan Area. International Journal of Remote Sensing, 23, 1775-1798. http://dx.doi.org/10.1080/01431160110075802

[4] Mundia, C.N. and Aniya, M. (2005) Analysis of Land Use/ Cover Changes and Urban Expansion of Nairobi City Using Remote Sensing and GIS. International Journal of Remote Sensing, 26, 2831-2849. http://dx.doi.org/10.1080/01431160500117865

[5] Ojigi, L.M. (2006) Analysis of Spatial Variations of Abuja Land Use and Cover from Image Classification Algorithms. In: Kerie, N. and Skidmore, A.K., Eds., Proceedings of the Mid-Term International Symposium Photogrammetry and Remote Symposium, WGVII/4, 162-168.

[6] Niger Delta Environmental Survey (1997) Final Report. Vols I-IV. Environmental Resources Managers, Lagos.

[7] Osei, A., Merem, E.C. and Twumasi, Y.A. (2006) Use of Remote Sensing Data to Detect Environmental Degradation in the Coastal Region of Southern Nigeria. In: Kerie, N. and Skidmore, A.K., Eds., Proceedings of the Mid-Term International Symposium Photogrammetry and Remote Symposium, WGVII/7, 51-63.

[8] Adegoke, J. and Akinyede, J. (2006) Niger Delta Satellite-Based Integrated Environmental Change Field Project. University of Missouri Kansas City (UMKC) - Nigeria Space Research and Development Agency (NASRDA) Joint Research Initiative. Executive Summary.

[9] Kabanza, F., Bourdua, D. and Bénié, G. (2001) Intelligent Image Analysis for Environmental Monitoring. Advances in Environmental Research, 5, 327-335. http://dx.doi.org/10.1016/S1093-0191(01)00083-1

[10] Burrough, P.A. and McDonnell, R.A. (2000) Principle of Geographic Information Systems. Oxford University Press, New York.

[11] Global Land Cover Facility (GLCF) (2005) Data and Products. http://glcfapp.umiacs.umd.edu:8080/esdi/index.jsp

[12] Tucker, C.J., Grant, D.M. and Dykstra, J.D. (2004) NASA’s Global Orthorectified Landsat Data Set. Photogrammetric Engineering \& Remote Sensing, 70, 313-322. http://dx.doi.org/10.14358/PERS.70.3.313

[13] Congalton, R.G. (1991) A Review of Assessing the Accuracy of Classifications of Remotely Sensed Data. Remote Sensing of Environment, 37, 35-46. http://dx.doi.org/10.1016/0034-4257(91)90048-B

[14] Anderson, J.R., Hardy, E.E., Roach, J.T. and Witmer, R.E. (1976) A Landuse and Land Cover Classification System for Use with Remote Sensor Data. Washington DC.

[15] European Environment Agency (2000) Corine Land Cover Technical Guide-Addendum 2000. Technical Report No 40.

[16] Jansen, L.J.M. and Di Gregorio, A. (2003) Land-Use Data Collection Using the “Land Cover Classification System”: Results from a Case Study in Kenya. Land Use Policy, 20, 131-148. http://dx.doi.org/10.1016/S0264-8377(02)00081-9

[17] Jensen, J.R. (2005) Introductory Digital Image Processing: A Remote Sensing Perspective. 3rd Edition, Pearson Prentice Hall, Upper Saddle River.

[18] DeFries, R.S. and Chan, J.C. (2000) Multiple Criteria for evaluating Machine Learning Algorithms for Land Cover 
Classification from Satellite Data. Remote Sensing of Environment, 74, 503-515. http://dx.doi.org/10.1016/S0034-4257(00)00142-5

[19] Multispec (2006) A Multispectral Image Data Analysis System. http://dynamo.ecn.purdue.edu/ biehl/MultiSpec

[20] Lillesand, T.M., Kiefer, R.W. and Chipman, J.W. (2004) Remote Sensing and Image Interpretation. 5th Edition, John Wiley, New York.

[21] Multispec (2001) An Introduction to Multispec. Version 5. Purdue Research Foundation. http://dynamo.ecn.purdue.edu/ biehl/MultiSpec/description.html

[22] Currit, N. (2005) Development of a Remotely Sensed, Historical Land-Cover Change Database for Rural Chihuahua, Mexico. International Journal of Applied Earth Observation and Geoinformation, 7, 232-247. http://dx.doi.org/10.1016/j.jag.2005.05.001

[23] Singh, A. (1989) Digital Change Detection Techniques Using Remotely-Sensed Data. International Journal of Remote Sensing, 10, 989-1008. http://dx.doi.org/10.1080/01431168908903939

[24] Yuan, F., Sawaya, K.E., Loeffelholz, B.C. and Bauer, M.E. (2005) Land Cover Classification and Change Analysis of the Twin Cities (Minnesota) Metropolitan Area by Multitemporal Landsat Remote Sensing. Remote Sensing of Environment, 317-328, 98. http://dx.doi.org/10.1016/j.rse.2005.08.006

[25] Chen, X., Vierling, L.A. and Deering, D.W. (2005) A Simple and Effective Image Normalization Method to Improve Landscape Change Detection across Sensors and Across Time. Remote Sensing of Environment, 98, 63-79. http://dx.doi.org/10.1016/j.rse.2005.05.021 